Wayne State University

DigitalCommons@WayneState

Theoretical and Behavioral Foundations of

Education Faculty Publications

Theoretical and Behavioral Foundations

$1-1-1999$

\title{
Measurement of Influence of the Teacher's Personality on Students in the Classroom
}

Shlomo S. Sawilowsky

Wayne State University, shlomo@wayne.edu

\section{Recommended Citation}

Novojenova, R., \& Sawilowsky, S. S. (1999). Measurement of influence of the teacher's personality on students in the classroom. Social Behavior and Personality: An International Journal, 27, 533-543.

Available at: http://digitalcommons.wayne.edu/coe_tbf/32

This Article is brought to you for free and open access by the Theoretical and Behavioral Foundations at DigitalCommons@WayneState. It has been accepted for inclusion in Theoretical and Behavioral Foundations of Education Faculty Publications by an authorized administrator of DigitalCommons@WayneState. 
SOCIAL BEHAVIOR AND PERSONALITY, 1999, 27 (5), 533-544

(C) Society for Personality Research (Inc.)

\title{
MEASUREMENT OF INFLUENCE OF THE TEACHER'S PERSONALITY ON STUDENTS IN THE CLASSROOM
}

\author{
Rima Novojenova and Shlomo S. Sawilowsky \\ Wayne State University, MI, USA
}

\begin{abstract}
The focus of this research is the assessment of pedagogical interaction as a dimension of the learning environment through the personal representation of a teacher in the student's personality, and the assessment of the nature and extent to which teachers are involved in changes of interpersonal dimensions of their student's personality. This was examined by the assessment of the shift in egograms of a teacher's students, as measured by the Interpersonal Check List (ICL). A $2 \times 9$ doubly multivariate repeated measures analysis of variance was conducted on the adult, parent, and child ego states as self-assessed by 187 students prior to the class period and after the class period, but still within the presence of the teacher. As hypothesized, the Time and the Class by Time results were statistically significant $(p<.05)$, indicating a general preclass to postclass change in ego state. The multivariate effect sizes averaged about .065 , which is subtle but detectible. The change in ego states were also significant $(p=0.018)$ when assessed by a singly-ordered row by column table, in terms of the number of students within each class who presented either an increase or decrease in the number of items representative of the Adult, Parent, or Child ego states on the ICL. The shift in ego state was also evidenced by the decrease (average Spearman's $r h o=.45$ ) in pre-post correlation (i.e., with the teacher in the classroom), as compared with test-retest (i.e., study hall with no teacher present) correlation (average rho of .86) of ego states.
\end{abstract}

The integration of Interpersonal Theory (Leary, 1957), Transactional Analysis (Berne, 1961) and Personalization (A. Petrovskiy \& V. Petrovskiy, 1980) was previously shown to be productive for the study of the unplanned imparting of a teacher's personality on students (Novojenova \& Sawilowksy, 1996). The approach of transactional reinterpretation via the Interpersonal Check List (ICL,

Rima Novojenova, Doctoral Student and Shlomo Sawilowsky, Ph.D., Professor and Department Chairman, Educational Evaluation and Research, College of Education, Wayne State University, MI, USA.

Please address correspondence and reprint requests to: Shlomo Sawilowsky, Ph.D., Educational Evaluation and Research, College of Education, Wayne State University, P.O. Box 48023, Oak Park, MI 48237, USA. Email: <shlomo@edstat.coe.wayne.edu> 
LaForge \& Suczek, 1955) permitted the development of a procedure for revealing the levels of the ego states in the self-perception of students. The method of "reflected subjectivity" (i.e., "analysis of the individual's personality through its representation in the life activity of other people, their motivations", V. Petrovskiy, 1985) was used to describe the impact of interpersonal teacher-student interaction in the teaching process. That is, the teacher's personal style of interaction is captured by comparing the level of actualization of ego-states of students before and after a class period.

The focus of this research is the analysis of pedagogical interaction as a dimension of the learning environment through the personal representation of a teacher in the student's personality. Also of concern is the assessment of the nature and extent to which teachers are involved in changes of interpersonal dimensions of their student's personality. Theoretical approaches and measurement of personality depend on the dominant aspect of the understanding of personality, and thus the approach taken is based on combining interpersonal theories of personality.

\section{Transactional Analysis}

Transactional Analysis (TA) provides a structural model of personality and a functional model (Berne, 1961, 1966). According to TA theory, the three primary ego states of Parent, Adult, and Child are used to describe the structure and function of personality. TA draws a parallel between the internal condition and interpersonal behavior.

TA theory describes a phenomenon of shift in interpersonal psychological functioning. Pointing to some limitations of assessing TA processes, Allen (1981) distinguished realms in which significant psychological shifts such as the experience of relationships and patterns of ego functioning and states of consciousness may occur. Allen (1981) further emphasized shifts in the experience of relationship which "may occur intra-psychically", that is, "internalized images of other persons", or "interpersonally, i.e., as observable in interactions with others". It is possible, then, to propose prototypic patterns of the relationship paradigm which defines the realm of ego states. Kernberg (1975, p. 34) studied shifts in ego states and its occurrence in relationships. Each dissociated ego segment contains certain object images, connected with a complementary self-image which was active at the time when internalization took place.

There are significant differences between individuals in their ego structure, and functioning and "differences within individuals in the quality of ego functioning depending upon the circumstances" (Bellak, Hurvich, \& Gediman, 1973). Shift defined by self-image and by object image is associated with a shift in major ego functioning. We propose to examine this in the current study by investigating how students react differently with regard to the same teacher, as discussed further below. 
The conceptualization of ego states is accompanied by a variety of methods for assessment purposes. For example, Thomson (1972) indicated that an individual can identify behavioral samples as reflecting one of the three major ego states. Dusay (1972) proposed the "egogram" (i.e., a graphic representation of the ego state) and further described the relative predominance of the types of ego state in an individual's typical functioning.

Several methods have been employed to obtain egograms. Steiner's (1974) approach was to have individuals well-versed in TA theory generate descriptions of their own personalities in egogram terms. Dusay ( 1977) obtained egograms by using a group to develop a consensus as to the egogram for a particular individual whom they knew well. The findings from studies by Brennan and McClenaghan (1978) indicated that reliable individual differences in characteristic ego states may be identified through self-report questionnaires.

Williams and Williams (1980) developed a procedure for the measurement of the ego state. The construction of egograms was based on the item pool of a commonly-used personality assessment procedure, the Adjective Check List (ACL; Gough \& Heilbrun, 1980). In responding to the ACL, a person was asked to select adjectives from among the 300 items, which he or she associates with the selfconcept to be described. Ego states could be assessed by a battery of psychological tests which are able to obtain information about interpersonal relationships (Williams \& Williams, 1980). The relationship paradigm could be assessed more directly by characterizing interpersonal situations, such in the Thematic Apperception Test (TAT).

\section{First Research Problem}

"The most important possibility is to assess the correspondence between shifts in relationships and shifts in ego functioning" (Allen, 1981, p. 250). Therefore, the first research problem relates to measurement of the shifts in relationships for a teacher and the shifts of egogram in her or his students.

\section{Personalization}

The theory of personalization conceptualizes personality as an ability of an individual to call for changes in the personality of other people. This approach describes personality as a subject of interpersonal relationship which exists in three psychological spheres:

- Intra - individual space: character, temperament, abilities, individuality

- Inter - individual space: space which appears in the group with mutual relation and interaction.

- Meta - individual space: aspect of the "ideal representation" of an individual in the life of other people 


\section{Second Research Problem}

A key concept of Meta-individual space is called "reflected subjectivity", which is an analysis of the individual's personality through its representation in the life activity of other people, their motivation, etc. In terms of assessment, there is a plethora of tools for the measurement of the first two categories (i.e., Intra- and Inter-). However, there is a paucity of assessment tools for the third category, Meta- individual space. In this study, we propose the use of the Interpersonal Check List for the measurement of reflected subjectivity.

\section{THE TEACHING PROCESS}

In the framework of theory of Personalization, teaching is viewed as a complex set of actions and cognitions which takes place in two main dimensions: Communication and Personalization. Communication is the process of transferring the information from the teacher to the student. Personalization is the process by which the teacher, in this case, is individually represented in the life of the student, and appears in the student's personality (V. Petrovskiy, 1985).

In the teaching process, personalization means that aspects of the teacher's personality are perceived by the students in such a fashion that it results in a form of transmission from the teacher's personality to the student's personality. The results of the teaching process appear in that dimension of personalization which brings about changes in the characteristics of the students, particularly in terms of their ego state, emotional changes, perceptual motives of behavior, and attitudes.

The study of personalization in the teaching process requires examining conditions in which teaching provides for the development of personality. We focus on aspects of cognition and behavior which show qualitative and quantitative changes in the ego state structure of personality in the student in the classroom. Assessment strategies can identify that meta-personal dimension of the teacher's personality which has a demonstrable objective effect on her or his students' interpersonal changes.

Our approach is consistent with the study of the classroom learning environment. Moos (1973) developed a scheme from which a subscale of the Individualized Classroom Environment Questionnaire (ICEQ, Rentoul \& Fraser, 1979) was derived for the measurement of the classroom environment. (Other instruments developed from Moos' scheme are found in Burden \& Fraser, 1993, Fraser, 1982, Fraser \& Fisher, 1986, and Trickett \& Moos, 1974.) In the classroom environment, "opportunities are provided for individual students to interact with the teacher and there is concern for the personal welfare and social growth of the individual" (Rentoul \& Fraser, 1979, p. 240). Moos' classification of human environments is purportedly captured in the personality subscale in terms of assessing "the nature and intensity of personal relationships within the environment. The extent to 
which individuals are involved in the environment and the extent to which they support and help each other" (Rentoul \& Fraser, 1979, p. 240). However, the framework of Personalization theory subsumes this subscale, and further expands to

- studying the personality's individuality;

- studying the personality as the subject of social activity and the system of interpersonal relations;

- $\quad$ studying the personality as an ideal representation in other people,

with particular emphasis on the ideal representation in other people.

\section{Third Research Problem}

In this study, we consider the assessment of the meta-personal aspect of the teacher's personality and its influence on students' interpersonal dimension of personality. Previous studies demonstrated that the study of the personality of teachers as individuals cannot be directly extrapolated to the characteristics of a teacher's personality as the subject of interpersonal relation with her or his students. The interpersonal factors of personality are those which a teacher uses to deal with students and to assess them in relation to others. This leads to a social environment in which the pedagogical process exists. This means that students can gain knowledge, as well as develop their personalities. The third aspect of constructing a teacher's personality has been studied both inside and outside individual interaction (i.e., ideal continuity of the subject in another's life personalization).

\section{THE CURRENT STUDY}

To restate the three research problems, in this study we are concerned with three issues. The first problem we consider relates to eliciting information about the correspondence between shifts in relationship of a teacher and the shifts of ego functioning in her or his students. The second issue is the efficacy of using the Interpersonal Check List for the measurement of reflected subjectivity. The third and final issue pertains to measuring the meta-personal aspect of the teacher's personality and its influence on students' interpersonal dimension of personality.

\section{SAMPLE}

Teachers and students participating in this study were selected from School Number 141, located in Moscow, Russia. Nine classes (from about 60) were selected to participate: Grades 5A $(n=23), 5 \mathrm{~B}(n=27), 5 \mathrm{~V}(n=20), 5 \mathrm{G}(n=27)$, 7A $(n=29), 7 \mathrm{~B}(n=24), 7 \mathrm{G}(n=26), 10 \mathrm{~A}(n=22)$, and 10B $(n=19)$, for a total of $N=217$ students. There were eight different teachers. Note that some classes 
were taught by several teachers. All of these teachers participated in a pilot program (the precursor to the current study) in September, 1985 (see Petrovsky and Novojenova, 1988).

\section{Procedures}

LaForge and Suczek (1955) noted "A common phenomenon in the field of personality research is the parallel development of personality theory and of tools for the measurement of the variables specified by that theory. Thus the TAT was developed in conjunction with Murray's need theory, the Rorschach began in part as an attempt to specify and define Jung's types.” The ICL was developed for study of Interpersonal Dimension characteristics, and therefore was selected in the current study.

The ICL was administered by a psychologist to the students participating in the study. The administrations occurred before the teacher came into the class, and again at the conclusion of the two hour class period, but still in the presence of the teacher. Each student was asked to assign a "+" if the student believed he or she possessed that quality, and a "-" if this quality was not possessed by the student. Note also that some students appeared in more than one class, which is further analyzed below. "Age norms" for assigning ego states to the adjectives on the ICL were previously developed by Petrovsky and Novojenova (1988) and Novojenova (1989).

\section{ReLiability OF THE ICL}

Cronbach Alpha was determined by deleting those ICL forms which were incomplete. This measure of internal consistency reliability was assessed at the pretest level, and the posttest level. The pretest reliability estimate was $.83(n=$ $162)$ and the posttest estimate was $82(n=129)$. Test - Retest analysis was conducted also on a group of 17 students who had a free class period of two hours. These students were tested at the beginning of the free time, and immediately thereafter. The test-retest estimate of reliability was .85 .

\section{RESULTS}

A $2 \times 9$ doubly multivariate repeated measures analysis of variance was conducted on the adult, parent, and child ego states as self-assessed by the students

prior to the class period and after the class period, but still within the presence of the teacher. The two independent variables were gender and class. The withinsubjects factor was time (i.e., the pre- and post-assessment of ego state). A full factorial model with unique sum of squares, and within + residual error term, was used via SPSS 8.0 for Windows 95/98 to analyze the data. The results are compiled in Table 1 below. 
TABLE 1

Multivariate Repeated Measures Analysis of Variance Of Student's Ego States Before and After Class Period.

\begin{tabular}{|c|c|c|c|c|c|}
\hline Test & Value & Approx. F & Hypoth. DF & Error DF & Sig. of $F$ \\
\hline \multicolumn{6}{|c|}{ Gender by Class by Time $(S=3, M=2, N=821 / 2)$} \\
\hline $\begin{array}{l}\text { Pillais } \\
\text { Hottellings } \\
\text { Wilks }\end{array}$ & $\begin{array}{l}.154 \\
.169 \\
.851\end{array}$ & $\begin{array}{l}1.148 \\
1.168 \\
1.158\end{array}$ & $\begin{array}{l}24 \\
24 \\
24\end{array}$ & $\begin{array}{l}507 \\
497 \\
484.95\end{array}$ & $\begin{array}{l}.286 \\
.266 \\
.276\end{array}$ \\
\hline \multicolumn{6}{|c|}{ Class by Time $(S=1, M=1 / 2, N=821 / 2)$} \\
\hline $\begin{array}{l}\text { Pillais } \\
\text { Hottellings } \\
\text { Wilks }\end{array}$ & $\begin{array}{l}.249 \\
.287 \\
.766\end{array}$ & $\begin{array}{l}1.913 \\
1.978 \\
1.947\end{array}$ & $\begin{array}{l}24 \\
24 \\
24\end{array}$ & $\begin{array}{l}507 \\
497 \\
484.95\end{array}$ & $\begin{array}{l}.006 \\
.004 \\
.005\end{array}$ \\
\hline \multicolumn{6}{|c|}{ Exact $\mathrm{F}$} \\
\hline $\begin{array}{l}\text { Pillais } \\
\text { Hotellings } \\
\text { Wilks }\end{array}$ & $\begin{array}{l}.016 \\
.016 \\
.984\end{array}$ & $\begin{array}{l}.907 \\
.907 \\
.907\end{array}$ & $\begin{array}{l}3 \\
3 \\
3\end{array}$ & $\begin{array}{l}167 \\
167 \\
167\end{array}$ & $\begin{array}{l}.439 \\
.439 \\
.439\end{array}$ \\
\hline \multicolumn{6}{|c|}{ Time $(S=1, M=1, N=821 / 2)$} \\
\hline $\begin{array}{l}\text { Pillais } \\
\text { Hotellings } \\
\text { Wilks }\end{array}$ & $\begin{array}{l}.052 \\
.054 \\
.052\end{array}$ & $\begin{array}{l}3.029 \\
3.029 \\
3.029\end{array}$ & $\begin{array}{l}3 \\
3 \\
3\end{array}$ & $\begin{array}{l}167 \\
167 \\
167\end{array}$ & $\begin{array}{l}.031 \\
.031 \\
.031\end{array}$ \\
\hline
\end{tabular}

The Class $\mathrm{x}$ Gender $\mathrm{x}$ Time result was not significant $(p>.05)$, indicating no significant interaction of the self-assessed ego states of adult, parent, and child. Similarly, the Gender x Time interaction was not significant, indicating that the self-assessed ego states do not change from prior to the class period until after the class period on the basis of gender. However, as hypothesized, the Time (a) and the Class by Time (b) results were statistically significant $(p<.05)$. That is, there was a general preclass to postclass change in ego state (a), and this difference can be attributed to the students' presence in different classes (b).

The multivariate test for homogeneity of dispersion matrices was significant (Boxs $M=898.858, F=1.823, d f=357,12686, p=0.000$ ). This is a cause for concern, as the assumption of multivariate homogeneity was violated. However, this is tempered somewhat as the univariate tests for homogeneity further indicated significance only for the adult ego state (Cochrans $C=.784, d f=9,18, p=$ $0.000)$, whereas the child $(p=.792)$ and parent $(p=.644)$ ego states met the underlying assumption of homoscedasticity.

The multivariate effect size and observed power at $\mathrm{a}=0.50$ for the combined effects (Class x Gender x Time), based on the three statistics reported in Table 1, were .052 and .72, respectively. For the significant multivariate results of Class $\mathrm{x}$ Time, and Time, the multivariate effect sizes and observed power were .083 and .99 , and .052 and .70 , respectively. 
Another way to analyze the ego state changes before and after the class period is to calculate the correlation of Students' ego state scores. Because the level of measurement is on an ordinal scale, the nonparametric Spearman's Rho correlation coefficient was applied. The baseline was the class of seventeen students who were given the ICL for the purpose of calculating the test-retest reliability (discussed above). The correlation of their test to retest ego state for Parent, Adult, and Child was compared with the correlations obtained for the 187 students who were given the ICL before and after the class period with their respective teachers. As noted in Table 2, the baseline correlations averaged .86, and dropped considerably to .45 as a result of the class period with their teachers.

TABLE 2

Correlational Analysis of Change in Ego States for Students With and Without the Presence of Their Teachers

\begin{tabular}{llcc}
\hline $\begin{array}{l}\text { Test-Retest } \\
\text { Ego State }\end{array}$ & $\begin{array}{l}\text { Spearman's } \\
\text { Rho }\end{array}$ & $\boldsymbol{n}$ & Sig. \\
\hline Parent & .77 & 17 & .000 \\
Adult & .97 & 17 & .000 \\
Child & .85 & 17 & .000 \\
Average & .86 & & \\
\hline Pre-Post & Spearman's & & \\
Ego State & Rho & $\boldsymbol{n}$ & Sig. \\
\hline Parent & .49 & 187 & .000 \\
Adult & .44 & 187 & .000 \\
Child & .42 & 187 & .000 \\
Average & .45 & & \\
\hline
\end{tabular}

The change in ego states can be assessed also in terms of the number of students within each class who present either an increase or a decrease in the number of items representative of the Adult, Parent, or Child ego states. Entries in Table 3 indicate the number of students who increased (+) or decreased (-) in their subscale scores for each ego state.

TABLE 3

Number of Students Who Increased (+) or Decreased (-) Adult, Parent, or Child Ego State After A Class Period

\begin{tabular}{|c|c|c|c|c|c|c|}
\hline \multirow{2}{*}{ Teacher } & & & tate & & \multicolumn{2}{|c|}{ Child } \\
\hline & + & - & & - & & - \\
\hline 1 & 11 & 17 & 12 & 15 & 14 & 12 \\
\hline 2 & 8 & 7 & 12 & 8 & 11 & 12 \\
\hline 3 & 8 & 8 & 11 & 7 & 6 & 7 \\
\hline 4 & 7 & 7 & 4 & 6 & 3 & 6 \\
\hline 5 & 18 & 10 & 23 & 8 & 26 & 6 \\
\hline
\end{tabular}


Table (continued)

\begin{tabular}{lrrrrrr} 
& \multicolumn{2}{c}{ Edult } & \multicolumn{2}{c}{ Ego State } & \multicolumn{2}{c}{ Child } \\
Teacher & + & - & + & - & + & - \\
\hline 6 & 7 & 5 & 9 & 7 & 6 & 5 \\
7 & 19 & 8 & 18 & 9 & 18 & 13 \\
8 & 10 & 5 & 10 & 5 & 9 & 8 \\
9 & 8 & 5 & 8 & 6 & 9 & 7 \\
\hline
\end{tabular}

A singly-ordered row by column table was constructed to analyze the number of students who changed in terms of ego state. The row represented the ordered category of decrease or increase in ego state, and the column represented the 9 classes. Analyses were conducted using StatXact 3.0 for Windows 95. The exact Kruskal-Wallis was conducted, and the associated $p$ value was obtained by a Monte Carlo of 10,000 samples. The exact statistic for Adult was 5.532, and the Monte Carlo estimate of the exact $p$ value was 0.018 , reflecting seven classes increasing $(+)$ and one class decreasing (-) in this ego state. Results via the same procedure for Parent was an obtained exact statistic of 48.95, $p=0.000$, with seven classes increasing and two classes decreasing in this ego state. For the Child ego state, the exact statistic was $.3685, p=.5438$, indicating no significant change.

\section{DISCUSSION}

Interpersonal assessment is an emerging field in interpersonal theory. Horowitz (1996) noted the importance of "an easily administered self-report inventory for describing different types of interpersonal problems" (p. 283). Strack (1996) called the development of "new assessment instruments" a "milestone in the history" of interpersonal theory. Wiggins and Trobst (1997) reviewed the development of interpersonal adjective scales, and noted, "advances in conceptualization have given rise to suggested new measurement procedures" (p. 112). In this study, we apply the well-known Interpersonal Check List in an attempt to measure delicate ego state shifts of students in the presence of their teachers.

This study demonstrated that the Adult, Parent, and Child ego states, as selfassessed by 187 students prior to a class period and after the class period, were significantly impacted and changed. As measured by the ICL, the effect size of this change averaged .068. According to Cohen (1988), an effect size of .2 is classified as small. Although the interpersonal changes, as evidenced by shift in ego states, are very subtle, yet they are detectible. This shift in ego state was evidenced also by the decrease (average rho $=.45$ ) in pre-post correlation, as compared with test-retest correlation (average rho of .86) of ego states. Further analyses indicated that, with the classroom as the unit of analysis, significant shifts were detected in Adult and Parent ego states. 
The implications are consistent with Horowitz's restatement of a postulate of the interpersonal model that "one person's actions elicit, evoke, and invite particular classes of reactions from the other person" (p. 284). In the current study, this was expressed as a measurable aspect of the metapersonal (Personalization) dimension of personality of classroom teachers and its impact on their students.

\section{REFERENCES}

Allen, J. G. (1981). Assessment of ego states, problems and prospects. Transactional Analysis Journal, 11, 247-251.

Bellak, L., Hurvich, M., \& Gediman, H. K. (1973). Ego functions in schizophrenics, neurotics, and normals. NY: Wiley.

Berne, E. (1966). Principles of group treatment. NY: Oxford University Press.

Berne, E. (1961). Transactional analysis in psychotherapy. NY: Grove Press.

Brennan, T., \& McClenaghan, J. C. (1978). The transactional behavior questionnaire. Transactional Analysis Journal, 8, 52-55.

Burden, R. L., \& Fraser, B. J. (1993). Use of classroom environment assessments in school psychology: A British perspective. Psychology in the Schools, 30, 232-240.

Cohen, J. (1988). Statistical power analysis for the behavioral sciences. (2nd ed.) Hillsdale, NJ: Erlbaum. Dusay, J. M. (1972). Egograms and the constancy hypothesis. Transactional Analysis Journal, 2, 37 41.

Dusay, J. M. (1977). Egograms. NY: Harper and Row.

Fraser, B. J. (1982). Development of short forms of several classroom environment scales. Journal of Educational Measurement. 19, 221-227.

Fraser, B. J., \& Fisher, D. L. (1986). Using short forms of classroom climate instruments to assess and improve classroom psychosocial environment. Journal of Research in Science Teaching, 23, 387413.

Gough, H. G., \& Heilbrun, A. B. (1980). The Adjective Check List manual. Palo Alto, CA: Consulting Psychologists Press.

Horowitz, L. M. (1996). The study of interpersonal problems: A Leary legacy. Journal of Personality Assessment, 66, 283-300.

Kernberg, O. (1975). Borderline conditions and pathological narcissism. NY: Ironstone.

LaForge, R., \& Suczek, R. F. (1955). The interpersonal dimension of personality: III. An interpersonal check list. Journal of Personality, 24, 94-112.

Leary, T. (1957). Interpersonal diagnosis of personality. NY: Ronald.

Moos, R. H. (1973). Conceptualizations of human environments.American Psychologist, 28, 652-665.

Novojenova, R. E. (1989). Study of transactional channels of interaction using a method of reflected subjectivity. Proceedings of the IV Congress of Psychology in Russia, Moscow, USSR.

Novojenova, R., \& Sawilowsky, S. (1996). Unplanned imparting of teacher's personalities to students in a Russian school. Psychological Reports, 78, 683-687.

Petrovskiy, V. (1985). Otrajonaye soobyektnost. Voprosy psikhologii, 4 [The principles of reflective subjectivity. Questions in Psychology, 4.

Petrovskiy, A., \& Petrovskiy, V. (1980). Psychology of the developing person. Moscow: Pedagogy. 
Petrovsky, V., \& Novojenova, R. E. (1988). Denamika vzroslich “rodetilskich," “deizkich," "cheir" ve somovospreyatee uchenekop cakproyavleneye personalizatzee ucheteela. In (A. Petrovsky Ed.) Psechologecheiskeye problema vezaemodeiyeseteveya kollektvea e lechnoste. Moscow: Academica peadagogechistkech nauk SSSR. [The dynamics of "Adult", "Child", and "Parent" aspects of students' self-perception as a manifestation of teacher's personalization. In A. Petrovksy (Ed.), Psychological problems of interaction of group and personality.] Moscow, USSR: Russian Federation Academy of Education, Institute of Psychology.

Rentoul, A. F., \& Fraser, B. F. (1979). Conceptualization of inquiry-based or open classroom learning environments. Journal of Curriculum Studies, 11, 233-245.

Steiner, C. (1974). Scripts people live. NY: Random House.

Strack, S. (1996). Introduction to the Special Series - Interpersonal theory and the interpersonal circumplex: Timothy Leary's Legacy. Journal of Personality Assessment, 66, 212-215.

Thomson, G. (1972). The identification of ego states. Transactional Analysis Journal, 2, 196-211.

Trickett, E. J., \& Moos, R. H. (1974). Personal correlates of contrasting environments: Student satisfactions in high school classrooms. American Journal of Community Psychology, 2, 1-12.

Wiggins, J. S., \& Trobst, K. K. (1997). Prospects for the assessment of normal and abnormal interpersonal behavior. Journal of Personality Assessment, 68, 110-126.

Williams, K. B., \& Williams, J. E. (1980). The assessment of transactional analysis ego states via the adjective checklist. Journal of Personality Assessment, 44, 120-129. 